\title{
Academic Literacy and Cultural Familiarity: Developing and Assessing Academic Literacy Resources for Chinese Students
}

\author{
Fiona Henderson and Paul A Whitelaw \\ Victoria University, Melbourne, Victoria, Australia
}

Fiona.henderson@vu.edu.au paul.whitelaw@vu.edu.au

\begin{abstract}
Academic dishonesty, including plagiarism, is a chronic problem. This paper reports the results of a project undertaken at a public funded university in Melbourne, Australia, in partnership with colleagues from a public funded university in Beijing, China, to combat this and other problems associated with academic literacy. The prime focus of the project was to improve students' understanding of and skills associated with academic literacy. This is important for all students in transition to higher education. The project evolved from an earlier pilot project which developed e-learning resources based on the Elaboration Likelihood Model (Petty \& Cacioppo, 2000). The pilot project's e-learning resources comprised examples from popular culture, particularly film, television, and music to engage students with the topic. Subsequent evaluation of that project found that it was not suitable for international students, especially those from China due to the cultural specificity of the resources. Consequently, a series of focus groups and workshops were conducted to identify how to improve these resources and make them accessible and meaningful for Chinese students. Outcomes of this project include the development and production of five elearning resources, each dealing with a different issue identified in the feedback.
\end{abstract}

Keywords: Academic literacy, plagiarism, Chinese students, multimedia resources, E-learning.

\section{Acknowledgements}

The authors wish to acknowledge the financial support of the Australian Teaching and Learning Council (ALTC Project Grant CG8-766). The opinions expressed are not necessarily those of the ALTC. We also wish to acknowledge the support and assistance of our colleague, Ms Penny Jose.

\section{Introduction}

Academic literacy is a complex, multi-component, multi-skill concept in tertiary education which, if all the skills are taught, should help address issues of academic dishonesty and plagiarism. Pla-

Material published as part of this publication, either on-line or in print, is copyrighted by the Informing Science Institute. Permission to make digital or paper copy of part or all of these works for personal or classroom use is granted without fee provided that the copies are not made or distributed for profit or commercial advantage AND that copies 1) bear this notice in full and 2) give the full citation on the first page. It is permissible to abstract these works so long as credit is given. To copy in all other cases or to republish or to post on a server or to redistribute to lists requires specific permission and payment of a fee. Contact Publisher@InformingScience.org to request redistribution permission. giarism has been an ongoing and growing global problem for many academics (Australian Higher Education Industrial Association, 2006; Carroll, 2004;

MacDonald \& Carroll, 2006). In recent years the increased incidence of plagiarism has been attributed to increased internet accessibility (Devlin, 2002) and behaviours such as copying and pasting, colluding and sharing writing, which 
have been made easier with technology. Plagiarism can be viewed as an outcome of misunderstanding or poor application of facets of academic literacy, such as critical thinking, critical reading, value of evidence, content knowledge, and expertise in academic writing. The practice of academic literacy skills may vary with educational and cultural backgrounds which also play contributing roles in the development of a student's understanding of and attitudes towards academic integrity.

With the advent of transnational education, universities in Australia have developed relationships with offshore universities, many of which are located in China (Department of Education Science \& Training [DEST], 2005). The teaching arrangements differ with each relationship but one strategy is for the early years of the qualification to be taught in China and the later years to be taught in Australia. The transition to both studying and living in Australia is complex and students thinking of undertaking study in Australia should undertake pre-departure academic orientation as well as on-arrival and as required "just-in-time" academic support (Dixon \& Henderson, 2005).

The relationship between the Melbourne based university and the Beijing based university is ten years old. Most of these particular Chinese students complete all of their Australian qualification in Beijing; however, each semester a small number make the journey to Melbourne to immerse themselves in the western culture. In either case there is a need to develop the academic literacy skills as they are prioritised and identified in the Australian qualification context. An innovative culturally appropriate approach to teaching using e-learning materials which deals with academic literacy may help to build the academic literacy of international students coming to Australia while also being useable and useful in China and elsewhere for those students seeking a western style education. Such a discussion about teaching practices which work or not and mutual professional development form the basis of an annual teaching and learning conference in China between the Australian university and its Chinese partner. This has been regarded as a very successful collaborative approach for introducing to each other new teaching and learning objects and strategies (Henderson, 2010; Henderson \& Pearce, 2011).

\section{Literature Review}

The project was informed by several bodies of enquiry including academic honesty and academic literacies, constructivist knowledge development, acculturation and assimilation, and the Elaboration Likelihood Model.

Academic dishonesty is an ongoing problem experienced across all higher education institutions. It is clear that plagiarism occurs in Australian higher education and that it appears to be widespread (Devlin, 2002; O'Regan, 2006). The literature notes that not enough has been done to improve levels of academic literacy and reduce academic dishonesty and that there is no universal approach or solutions to the problem. On the other hand, definitions of what actually constitutes academic literacy and plagiarism vary, leading to confusion and misunderstanding of these concepts by students (Ercegovac \& Richardson, 2004). The authors' experience suggests that for students academic honesty is an archaic, irrelevant academic convention that does not apply in the "real world" (Brimble \& Stevenson-Clarke, 2005). This view is often reinforced by the means by which Universities inform students about plagiarism and other forms of academic dishonesty with rules, regulations, and repercussions documented in text heavy websites (O'Regan, 2006). This has the dual effect of alienating students who are not familiar with text-only discourse as well as those students for whom English is not their first language. This situation may be exacerbated by cultural differences experienced by international students when studying in Australia: "it is even more difficult for international students, writing in a second language and also, often, from a cultural background of different assumptions about the correct use of sources" (Chanock, 2003, p. 23). 
Special attention must be paid to the understanding of first-year students and others in transition into higher education. For them to succeed in their studies they need to acquire and develop the skills that will allow them to seek and gain information and apply critical thinking in the processes of evidence and argument building as they apply their newly acquired knowledge (Lupton, 2008). To assist in the acquisition of these skills, amendments to curricula as well as innovative pedagogical approaches are required. These new approaches must reflect an understanding of student culture, behaviour, needs, and other factors in order to engage students in the learning process (Hunter, 2006).

International students, who represent a large cohort in the Australian education system, often find transition and acculturation in Australia challenging (Best, Hajzler, \& Henderson, 2007). Elearning and other programs should, and have in some instances, be developed in order to reduce stress for international students and assist them in settling into their studies. It has been noted that transition is difficult for students from Asia, especially China, as traditional Chinese higher education concentrates on knowledge accumulation, with critical reading and critical thinking to present one's own argument by drawing on a range of evidence not seen as familiar concepts for its students (Zhuang, 2009). Issues concerning academic literacy and plagiarism are reported to be widespread among international students, but are not limited to them; this is an ongoing problem in higher education generally.

Some institutions have focused on "practical solutions" by offering instruction on paraphrasing and the technical aspects of correctly citing work. However, these approaches seem to miss the key point, particularly when juxtaposed against the principles of higher education, which is that students need to develop an understanding of the underlying theory and principles of academic literacy and academic honesty, rather than learn simple tasks and processes, often without understanding (Emerson, Rees \& MacKay, 2005; Valentine, 2006).

It is notable that there is not much discussion of the underlying principles of academic honesty and academic dishonesty, especially plagiarism (Yeo, 2006). Exacerbating this is the typical approach of official warnings. Guidelines and policies do not appear to be enough to help students understand and develop the skills necessary for them to avoid plagiarism (O'Regan, 2006, p. 114).

Some authors have called for changes to the way students approach the issue of academic dishonesty: "Students need to develop a stronger commitment to the educational process, and possess, or activate, an internalised code of ethics that opposes cheating to deal with the problem of plagiarism more effectively" (Davis, Grover, Becker \& McGregor, 1992, p. 17). Davis and his colleagues argue that there is a key role here for academics who should routinely discuss with students why they should not cheat, rather than just telling them "don't cheat".

The constructivist approach (Biggs, 1994) provides a point of differentiation between the reproduction of facts, or fact-like statements, and the demonstration of an understanding of subject content. This understanding is often found wanting when students are called upon to demonstrate a depth of understanding in assignments and examinations. Students entering university are also required to adopt a very specific style of academic writing in which they might not be skilled, or of which they are not fully aware (Jackson, Watty, Lu \& Lowe, 2006; Kaldor \& Rochecouste, 2002). Additionally, it is likely that the academic writing style promoted will be modeled on journal articles that are prescribed reading. Unfortunately, for novice students, many of these articles and texts are written for an audience of academic peers in such fora as academic conferences and journals (Kaldor \& Rochecouste, 2002).

Further, Biggs (2003) contends that students will focus on material evaluated in summative assessment and disregard any and all other "extraneous" material in a unit of study. This view of what is important can lead to a search for marks without concomitant understanding, which in turn can lead to progression through a degree without expected academic development. Embed- 
ding academic literacy skill development within the taught curricula, which are valued explicitly in assessment tasks, provides a strategy by which this problem may be addressed.

From a psychological perspective, a student's transition in higher education can be heavily influenced by a range of personal factors, such as a student's personality (Lennings, Burns \& Cooney, 1998), self efficacy (Eronen \& Nurmi, 1999), and cultural background (Barron \& Arcodia, 2002). An individual might therefore be influenced by an orientation program which introduces the concepts of academic literacy within a framework that appeals to them and relates to their personal experiences and world view.

Similarly, extensive research into both similarities and differences among students in the Chinese student cohort is reported by Marton, Dall'Alba and Tse (1996), Volet and Renshaw (1996) and Zhang and Sternberg (2000). This research suggests that as Chinese students share common cultural backgrounds, they will appreciate relevant common cultural references. However, like their western counterparts, they are individuals with idiosyncratic personalities and learning styles and thus will respond individually to various stimuli.

The goal of this project is to develop the messages and media that resonate with students so that they become aware of, receive, and adopt the key messages of academic literacy and their attendant practices. One approach to this engagement lies in the use of the Elaboration Likelihood Model (ELM) (Petty \& Cacioppo 2000). The ELM suggests that individuals process messages in one of two ways, high elaboration or low elaboration wherein elaboration is "the extent to which a person carefully thinks about issue-relevant arguments contained in a persuasive communication" (p. 191).

With high elaboration, also known as the central route, messages are carefully scrutinised and evaluated for logic, internal consistency, and merit. With low elaboration, also known as the peripheral route, individuals are less motivated to think about arguments and tend to concentrate on peripheral clues to assess the relevance and credibility of the source and, by implication, the merit and value of the information.

Petty and Cacioppo (2000) argue that the high elaboration route is taken when the subject matter is deemed relevant and vital to the recipient. The low elaboration route is employed when the recipient deems the subject matter not entirely relevant and so relies on a "lazy, short hand" of visual and audio cues to assess the merit of the argument (p. 192). In this sense, the situation concerning academic literacy is particularly perplexing. It can reasonably be assumed that, given the gravity of the consequences involved, students should be keenly interested in understanding all of the issues related to academic literacy and honesty and its negative corollary, academic dishonesty (including plagiarism), especially where punishment is involved. However, the evidence suggests that increasing numbers of students do not heed the message. It may be that, despite its importance, students find most advice on academic honesty and especially how to avoid plagiarism to be so inaccessible that they do not exert the necessary effort to develop a deep and enduring understanding of the fundamental concepts and principles involved. They may tactically develop some technical skills in the correct methods of citing work without strategically developing the understanding necessary to value and adopt the underlying principles of academic literacy and academic integrity.

The ELM model suggests that the peripheral route can be used to firstly secure the recipient's attention and then engage them through the central route. For this project we are arguing that academic literacy is likely to be more accessible via culturally relevant and engaging multi-media e-learning resources rather than through dense, stentorian text, as is often seen in university academic integrity policies and anti-plagiarism material. Therefore, the student would move from the more accessible peripheral route of multimedia resources to the central route characterized by more formal documents about academic integrity and plagiarism and consequently more com- 
pletely engage with and develop a stronger appreciation of academic literacy and integrity once engaged via the peripheral.

Finally, in order to facilitate the acquisition of a deep understanding and the adoption of appropriate, affective outcomes and values, students need to develop skills in academic practice that are predicated on self-reflection and meta cognition. These fundamental, but high-level, skills cannot be acquired without structured guidance by well-supported and resourced teachers.

This literature informed a key aim of the project. It sought to provide the students with philosophical and conceptual understanding, practical, technical instruction and interactive feedback via a suite of multimedia resources.

\section{Project Setting}

One of the key areas of concern in higher education is academic literacy, which involves critical thinking, creativity, and academic honesty. These aspects have been of growing concern in recent years at a multi-disciplinary institution in Melbourne, with students from a wide range of backgrounds (Borland \& Pearce, 1999) that include the socially less advantaged suburbs of a major metropolitan centre, interstate, and international students, especially students from China.

In response to these issues the university adopted several innovative approaches. One was a pilot project which developed e-learning resources that included a web site, video and audio recordings, and a self paced, formative quiz. These resources used modern pop culture, particularly television, movies, and music, as well as humour to convey to students some of the key messages in academic literacy. The pilot project received very positive feedback as well as enquiries from academics beyond Melbourne wanting to use the material in its current form. Other academics enquired about the feasibility of adapting the resources for their own institutions and specific student cohorts. However, despite this positive feedback, the resources were criticized because most of the western popular culture references were lost on international and especially Chinese students. A project was launched which sought to address the specific cultural needs of Chinese students and is thus seen as the next step in the progression of our ongoing work on academic literacy.

\section{Research Aim}

The Melbourne-based and Chinese-based universities conducted the project, which aimed to develop and evaluate a range of e-learning resources that were intended to specifically assist Chinese students in Australia and other English-speaking countries, as well as those studying in a western setting in China, to develop a deep understanding of academic literacy. In this setting, the constituent components of academic literacy such as critical thinking, referencing, paraphrasing and academic integrity were highlighted. This scope was specifically chosen to help students address the challenges, and resist the temptations, of plagiarism.

This paper reports on the evaluation of the pilot project and how that evaluation informed the next phase of the project, the development of a suite of five e-learning resources to explicitly meet the needs of Chinese students, and their subsequent evaluation.

\section{Methodology and Techniques}

The reported project was initially driven by the feedback from an earlier pilot project. That feedback informed a new, multi stage project, reported here, that involved working with teachers who speak both Chinese and English and were native speakers in one or other language. This workshop identified effective messages that can be used to convey the themes of academic literacy to Chinese students. Guided by Homewood (2009), it also identified the most appropriate media, 
stylistic approaches, tone, and cultural references to address the particular needs of Chinese students.

\section{Evaluating the Pilot Project to Inform the New Project}

In order to set the scene for the project at hand, the top line results of the pilot project shall be presented. The detailed results of that work are reported elsewhere (Whitelaw et al., 2010). In the first instance, the pilot project was tested with a second year undergraduate cohort. In terms of academic performance, the grade distribution for this cohort was almost identical to that of previous cohorts who were not exposed to the resources. Whilst a small number of incidents involving academic dishonesty are identified each semester, there were no such incidents within this cohort. It is, however, possible that this may be a consequence of increased attention and focus on academic dishonesty and plagiarism during the project.

A student survey and a survey of academics, using a questionnaire comprised of 18 closed item questions based on a five-point Likert style scale relating to the mechanics of the website and video as well as their experience in using the resources, was conducted. There was also an opportunity for the students to offer their opinions via open-ended comments. A total of 143 students provided responses on 11 questions and 45 students provided answers on all 18 questions. A total of 27 academics responded to the invitation to participate in this evaluation. The results of the student and academics' survey in the pilot project highlighted two aspects that are worth noting:

- the "mechanical" aspects (those dealing with the speed of download, the ease of reading the website) generally scored higher than the qualitative aspects (being interesting or engaging) or impacts (changing behaviours),

- the results of both students and academics were very consistent with little difference, except in three areas:

0 the students tended to be more critical of the appeal of the content,

o the students tended to be more optimistic about not engaging in plagiarism in the future, and

- a bare majority (54\%) of students preferred that the resources be optional whereas $75 \%$ of the academic respondents wanted the resources to be compulsory.

The e-learning resources were further evaluated by way of a series of focus groups including an expert panel of academics who have experience teaching in China and Australia. As well, a series of focus groups comprising first, second and final-year Chinese students who have successfully studied both in China and in Australia was also conducted.

The feedback was generally positive, although several issues were identified. Respondents suggested that placing English subtitles of speech and monologues at the bottom of the screen would enhance the Chinese students' understanding of the content. Further, it was noted that the examples and exemplar characters are unfamiliar to Chinese students and thus were not properly understood. As such, these characters and references should be replaced by characters with whom Chinese students would be familiar. The use of at least one Chinese actor and less complex language delivered more slowly were also deemed beneficial.

The survey results and information from the various focus groups in the pilot project was used to establish a framework of issues, sensitivities and aspects of culture which are both relevant to academic literacy and academic honesty as well as meaningful and relevant to Chinese students that needed to be addressed in developing the new resources. The resultant project, the focus of this paper, was based on that framework. 


\section{Developing the New Resources - The Project under Investigation}

For the resultant project, which is the focus of this paper, a workshop comprising bilingual teachers with considerable expertise in teaching Chinese students was used to brainstorm and gather input relating to content, management, and methods to maximise efficacy and sustainability of resources developed in the project.

Poor language skills emerged as one of the main barriers to critical reading and critical thinking amongst Chinese students, combined with cultural, moral, and ethical differences in their understanding of academic writing. Cultural issues, such as the need to protect "face" and respect authority, general reticence, and reluctance to volunteer if asked were raised. It was also noted that students do not receive formal instruction in the development of these skills and values. These issues could be addressed by providing context-specific cultural maps and strategies to help the students negotiate their way through this new, western academic culture. However, these resources must not be allowed to devolve into simple prescriptions that must be followed without question. They must be used as part of a rigorous and integrated process of professional, academic, and personal development.

Given the complexity of the issues involved, it was felt that it may be better to be initially prescriptive and subsequently encourage more creativity as students' skill levels increase. This is analogous to Bloom's taxonomy (Bloom, Englehart, Furst, Hill \& Krathwohl, 1959) wherein academic progression is marked by an increasingly sophisticated and deepening understanding of the subject matter at hand. It is also consistent with Biggs work on constructive alignment (2003).

One of the key themes to emerge from the workshop was that the project was not dealing with an homogenous group of students with a single, uniform problem. Within the Chinese student cohorts there is considerable diversity in background, suggesting that there are several issues which will need several solutions. Consequently, a single resource was deemed not adequate. Moreover, the matter of academic integrity needs to be reinforced over the whole period of the student's education, requiring a whole-of-university and a whole-of-curriculum strategy.

Teaching and learning strategies discussed included the need for discipline-specific tasks and the provision of examples and resources. It was noted that it may be more helpful to create smaller resources which could be adapted to different disciplinary settings and subject areas rather than one, single, large resource that would not be as flexible. It was further considered that face-toface delivery would be much more effective than just "sticking it on the web and directing the students to look at the website" and that the use of more guided and structured e-learning activities and assessment tasks in conjunction with face-to-face delivery would increase student understanding. Finally, it was noted that it cannot be assumed that teachers are equally able to teach academic literacy and that there is some reluctance on the part of teaching staff to engage in innovative teaching methods and processes that are not directly related to their area of specialisation. The issue of ensuring that resources are used by both teachers and students must be addressed and awareness of the existence of those resources and their integrated usage must be increased within the context of normal, sustainable teaching practices.

The resultant resources thus had the following characteristics: they were culturally specific with Chinese actors and students playing key roles in the video vignettes, they used examples directly from Chinese history, they were broken up into small segments which can facilitate classroom discussion, and they address the philosophical, conceptual and operational and tactical aspects of academic literacy. 


\section{Outcomes: The New Resources}

The project produced five e-learning resources which address the different challenges encountered by Chinese and other international students in their efforts to understand academic literacy and academic integrity. The resources can be found at the following website (http://tls.vu.edu.au/altc/studentresources.cfm) and are readily available under a creative commons agreement.

\section{Richard \& Kim Encounter Academic Literacy (Video)}

This video acts as a prologue and epilogue to The Road to Academic Literacy and as such can be used to stimulate class discussion. This video adopts a proactive stance to connect the theoretical to the everyday as two real-life international students encounter the feelings of puzzlement, confusion, exasperation, and anxiety as these emotions are typically experienced by an undergraduate student. This perspective helps establish the relevance and legitimacy of this resource for students.

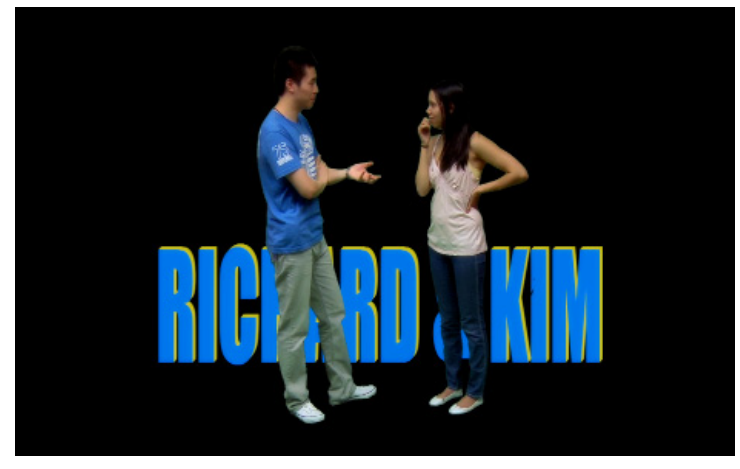

The three chapters of the video, each of approximately ten minutes length, are best viewed on separate occasions to avoid student information overload. This approach builds serial interest and scaffolds the development of skills and understanding.

\section{The Road to Academic Literacy (Video)}

This "new" video is a re-edited, revised version of the original Australian pilot project referred to above which contained original footage and sound from modern movies, television shows, and audio recordings. The new material now complies with copyright law and as such is available under creative commons guidelines to colleagues beyond Australia, as are all of these new resources. The video addresses key theoretical concepts using interactive examples with some Chinese subtitles for particularly challenging concepts.

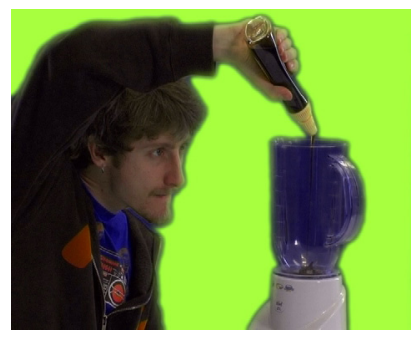

Two students enter the world of academia and learn that success involves the application of advanced principles that include critical thinking, evidence-based creativity (as opposed to speculative guessing) and academic honesty that they must acquire, understand and apply across all their studies in order to graduate and gain satisfactory employment.

\section{April's Journey (Video)}

This video addresses the issues of transition and acculturation. In 2008, April travelled from China to study in Melbourne, Australia. Struggling with homesickness, culture shock, communication issues and a new city, new social circle, and new approach to study, April learns more about herself and her peers than she ever expected. The video is in two parts and each part runs for about six minutes with an "intermission" which can be used to generate class discussion and personal reflection.

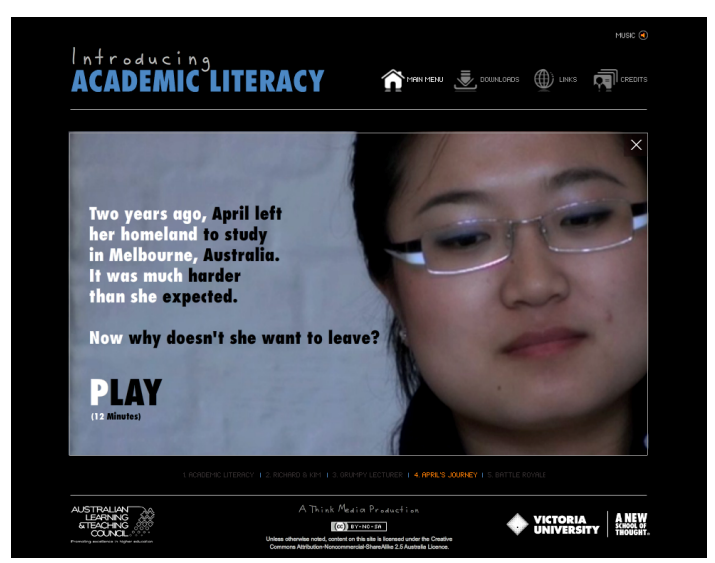




\section{'Behind Closed Doors' with Grumpy Lecturer: Improving Your Assignment (Video)}

This resource is designed to translate theory into practice. After outlining the overall academic philosophy in The Road to Academic Literacy, and some conceptual issues in Richard \& Kim Encounter Academic Literacy, and engendering self confidence in April's Journey, this resource incorporates technical and practical instruction and interactive feedback. It showcases specific tips to help students to improve their written assignments.

The presence of the curious Chinese student and his direct questioning of the "Grumpy Lecturer" during the process of marking his work helps improve the student's understanding of what exactly is required in

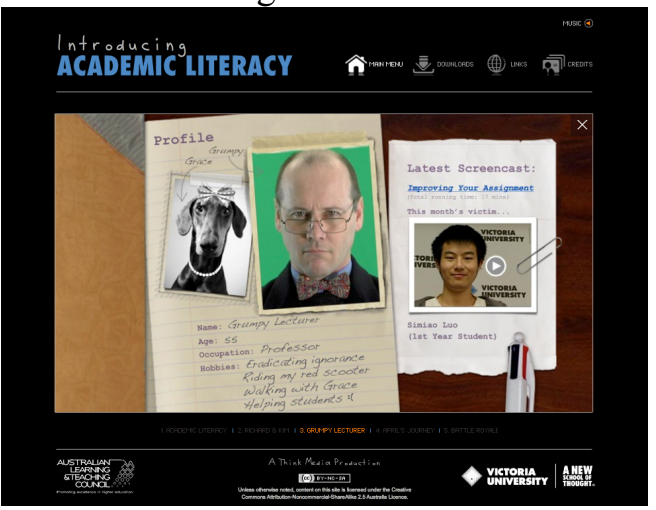
his assignment.

The video is 18 minutes in length, but can be viewed in six segments, each of approximately three minutes dealing expressly with writing clearly, using examples, quoting, paraphrasing, referencing, and writing logical conclusions.

\section{'Battle Royale' with Grumpy Lecturer, PhD (Comic Strip Serial)}

The Grumpy Lecturer gives words of wisdom on a wide range of everyday study issues in this 16 episode graphic novel (comic). The setting is an ancient ping pong tournament at the top of the world, in the style of of Shangri La meets Kung Fu. The serial has been designed to engage students with the topic and alert them to the existence of the resources. Each episode can be used in Powerpoint format as a weekly tip at the start of lectures or in pdf as a weekly e-learning resource or handout.

However, it can also be produced as a printed booklet during orientation to promote awareness of the existence of

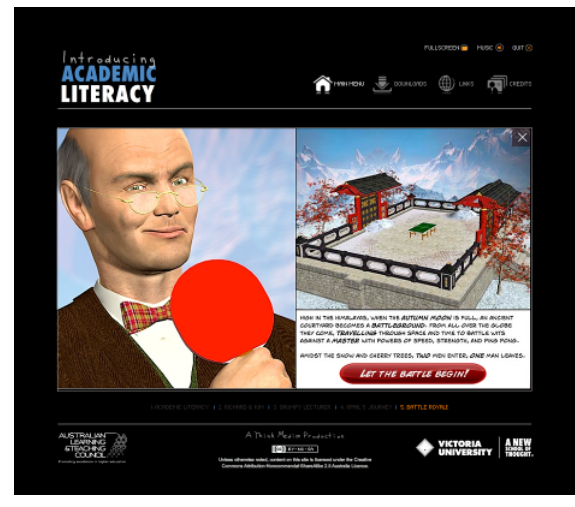
academic issues and the entire Introducing Academic Literacy digital resources. With English and Chinese versions side by side, the comic also doubles as an engaging tool for language exercises.

\section{Project Evaluation}

\section{Student Evaluation}

One hundred and thirty Chinese students in Australia and China participated in a series of focus groups to discuss the resources developed for this project. Focus group questions are in Appen$\operatorname{dix}$ A.

The feedback for the Richard \& Kim Encounter Academic Literacy (video) was generally positive, with students appreciating the rich colourful production, pictures, style of humour, and music. They reported that the examples were good and appreciated the combination of Chinese and western academic thinking. They said it was good to know that many students, not just themselves, felt the same way about the issues raised in the video. 
The students indicated that the April's Journey video gave them the confidence and encouragement to adjust to their new environment and culture. In particular, it can help them overcome their language barriers and better understand communication and cultural differences. Students recognised the importance of communication, listening and speaking, teamwork and friendship, and self-study as well as building a strong supportive network in the broader process of adopting academic literacy practices.

Students thought the comic strip serial, 'Battle Royale' with Grumpy Lecturer, was attractive, colourful, and eye catching; they were eager to read it. They readily identified and acknowledged the important of its themes. Comics, as media, were favoured by the vast majority of students in the target groups, but there was consensus that it should be delivered one topic (page) at a time.

\section{Academic Staff Evaluation}

A follow up workshop sought feedback on the resource materials created for the project from the reference group, teaching and learning experts, the team involved in the development of the resources, and colleagues and team partners from both Australia and China, a total of more than 20 colleagues. Participants were asked to comment on key issues raised by the resources and provide feedback on their potential use as well as areas for improvement. See Appendix B for indicative questions.

Participants described Richard \& Kim Encounter Academic Literacy as an interesting and entertaining video, reporting that it presented the four principals of academic literacy (application and persistence, critical thinking, evidence-based creativity, and academic honesty) in an engaging and integrated manner.

The overall response to the April's Journey video was that it is a very powerful, useful resource and could be adopted in a wide range of situations. Participants commented on the effective use of the student voice and experience, particularly the sentiment that "I have to make mistakes to learn to improve my English".

The participants thought the instructional video 'Behind Closed Doors' with Grumpy Lecturer: Improving Your Assignment was "brilliant", practical, and clearly explained. It was felt that it unified, while individually addressing, all the issues which confront students in preparation of their assessments. The order of presentation of the topics was logical and flowed well.

General feedback on the use of the comic 'Battle Royale' with Grumpy Lecturer, PhD, as one of the range of tools by which the message of academic literacy was conveyed was positive. Participants agreed that the idea of a fantasy theme and "master" or "superhero" was good and something which would engage the Chinese students. The proposition that weekly or regular use of selected pages of the series to reinforce aspects of academic literacy was considered particularly helpful.

Overall, feedback from the workshops was positive, with participants commenting that it was a most stimulating and potentially very valuable set of learning resources.

The ELM's central approach, which assumed that students would take messages about plagiarism seriously because it is a serious topic has been found wanting. However, by getting students to focus on the concepts of academic literacy via a series of engaging videos, graphic novels, and web pages supports to an extent the value of the ELM; the peripheral approach has proven to offer a means by which students may engage with these important concepts and adopt the appropriate behaviours. 


\section{Conclusion}

The project produced five media outputs: Richard \& Kim Encounter Academic Literacy (video), The Road to Academic Literacy (video), April's Journey (video), 'Behind Closed Doors' with Grumpy Lecturer: Improving Your Assignment (video), and 'Battle Royale' with Grumpy Lecturer, $\mathrm{PhD}$ (comic strip serial). These media resources each address different but related aspects of academic literacy, while also taking into account the particular needs of international students, and especially those from China.

The feedback from workshops and interviews with students was highly positive for each of the resources. The students understood the topics well and were engaged with and encouraged by the material to improve their academic literacy. Colourful, interactive material about academic literacy was found to be more accessible and encourage learning as a group than plain text resources or labour intensive, embarrassing, one-on-one instruction.

The aim of this project was to develop a suite of e-learning resources to improve the academic literacy and academic integrity of Chinese students. Whilst testing the efficacy of any learning resource is somewhat problematic, the project team is confident that the feedback from the focus groups, the interviews, and the results of the online survey suggest that the resources developed in this project have the potential to improve the understanding of concepts of academic literacy and plagiarism across the higher education sector.

Various forms of evaluation suggest that these resources alone will not eradicate academic illiteracy, and especially academic dishonesty. However, it appears that they can significantly contribute to increased understanding, acceptance, and implementation of the concepts of academic literacy by Chinese students in a western higher-education environment. In turn, this should enhance the academic quality of Chinese students' work and reduce the temptation to engage in academic dishonesty.

This Australian university, like many other Australian universities, has a diverse student cohort which has multiple entry points to access the various courses on offer (Caldwell, 2009). This combination of student diversity and entry point variety presents many challenges to be overcome in ensuring that all students are appropriately introduced to and adopt the key values and principles of academic literacy. The introduction of academic literacy skills, at the earliest possible point, and with the expectation that such skills will be embedded in the pedagogy, should support successful academic transition (Dixon \& Henderson, 2005).

There is strong evidence to suggest that successful transition and orientation e-learning and learning objects lead to improved student acculturation and satisfaction, which in turn can lead to improved retention, progression, and timely completion (strategies which are cited in Gabb, Milne $\&$ Cao, 2006). Conversely, poor or nonexistent transition and orientation programs and resources can lead to unacceptable levels of student attrition.

Plans are now in place to formally introduce the resources into normal teaching practice. This will first be done by embedding them into two first year undergraduate units and one second year undergraduate unit at both the Australian and Chinese universities.

\section{References}

Australian Higher Education Industrial Association. (2006). Plagiarism a valid reason for dismissal. Australian Higher Education Industrial Association, 76 (28 February), 22.

Barron, P., \& Arcadia, C. (2002). Linking learning style preferences and ethnicity: International students studying hospitality and tourism management in Australia. Journal of Hospitality, Leisure, Sport and Tourism Education, 1(2), 15-27. 
Best, G., Hajzler, D., \& Henderson, F. (2007). Communicating with Chinese students offshore to improve their transition and adjustment to Australia - A pilot program. Journal of Academic Language and Learning, 1(1), 78-90.

Biggs, J. B. (1994). Student learning research and theory - Where do we currently stand? In G. Gibbs (Ed.), Improving student learning - Theory and practice. Oxford: Oxford Centre for Staff Development.

Biggs, J. B. (2003). Teaching for quality learning at university: What the student does. Berkshire, UK: The Society for Research into Higher Education, Open University Press

Bloom, B. S., Englehart, M. D., Furst, E. D., Hill, W. H., \& Krathwohl, D. R. (1959). Taxonomy of educational objectives: The classification of educational goals. Handbook 1: The cognitive domain. New York: David McKay.

Borland, H., \& Pearce, A. (1999). Valuing diversity: Experiences and achievements of NESB students at Victoria University. Melbourne: CEDS Victoria University.

Brimble, M., \& Stevenson-Clarke, P. (2005). Perceptions of the prevalence and seriousness of academic dishonesty in Australian universities. The Australian Educational Researcher, 32(3), 19-44.

Caldwell, H. (2009). Student segmentation study: An analysis of the student population at Victoria University. Melbourne: Victoria University.

Carroll, J. (2004). Deterring, detecting and dealing with plagiarism. Teaching News. Retrieved from http://www.brookes.ac.uk/services/ocsd/2 learntch/plagiarism.html

Chanock, K. (2003). Before we hang that highwayman - The LAS advisers' perspective on plagiarism. In H. Marsden \& M. Hicks (Eds.), Educational integrity: Plagiarism and other perplexities: Proceedings of the inaugural educational integrity conference (pp. 21-22). Adelaide: University of South Australia, November, 21-27.

Davis, S., Grover, C., Becker, H., \& McGregor, L. (1992). Academic dishonesty: Prevalence, determinants, techniques, and punishments. Teaching of Psychology, 19(1), 16-20.

Department of Education Science \& Training (DEST). (2005). A national quality strategy for Australia transnational education \& training. Retrieved from http://aei.dest.gov.au/AEI/GovernmentActivities/QAAustralianEducationAndTrainingSystem/QualStra t pdf.pdf.

Devlin, M. (2002). Minimising plagiarism. Melbourne: Centre for the Study of Higher Education, The University of Melbourne. Retrieved from http://www.cshe.unimelb.edu.au/assessinglearning/03/plagMain.html

Dixon, J., \& Henderson, F. (2005). Improving language and learning support for offshore students. Canberra: DEST/AVCC.

Emerson, L., Rees, M., \& MacKay, B. (2005). Scaffolding academic integrity: Creating a learning context for teaching referencing skills. Journal of University Teaching and Learning Practice, 2(3a), 12-24. Retrieved from http://jutlp.uow.edu.au/

Ercegovac, Z., \& Richardson, J. V. (2004). Academic dishonesty, plagiarism included, in the digital age: A literature review. College \& Research Libraries, 65(4), 301-318.

Eronen, S., \& Nurmi, J. E. (1999). Life events, predisposing cognitive strategies and well-being. European Journal of Personality, 13(2), 129-148.

Gabb, R., Milne, L., \& Cao, Z. (2006). Understanding attrition and improving transition: A review of recent literature. Retrieved from http://tls.vu.edu.au/PEC/PEC docs/Understanding\%20attrition.pdf

Henderson, F. (2010). Enriching partnerships: Research and innovation to support student success [Conference Report] Retrieved from http://tls.vu.edu.au/vucollege/research_and_projects/2010\%20docs/BOS32-190810-06b.pdf 
Henderson, F., \& Pearce, A. (2011). Collaborative research with Chinese teaching partners to further student academic language and learning support. In C. Clark \& J. Zhou (Eds.), Internationalization of China's higher education: Challenges for Sino-foreign joint educational programs/institutions. Shenyang, China: Liaoning University Press.

Homewood, J. (2009). Development and evaluation of resources to enhance skills in higher degree research supervision in an intercultural context. Retrieved from http://www.altc.edu.au/printpdf/projectdevelopment-evaluation-resources-macquarie-2007

Hunter, M. (2006). Lessons learned: Achieving institutional change in support of students in transition. New Directions for Student Services, 114. Retrieved from http://0www3.interscience.wiley.com.library.vu.edu.au/cgi-bin/fulltext/112660797/PDFSTART

Jackson, M., Watty, K., Yu, L., \& Lowe, L. (2006). Assessing students unfamiliar with assessment practices in Australian universities (Accounting). Retrieved from http://www.olt.gov.au/project-assessingstudents-unfamiliar-rmit-2005

Kaldor, S., \& Rochecouste, J. (2002). General academic writing and discipline specific academic writing. Australian Review of Linguistics, 25(2), 29-47.

Lennings, C. J., Burns, A. M., \& Cooney, G. (1998). Profiles of time perspective and personality: Developmental considerations. The Journal of Psychology, 132(6), 629-641.

Lupton, M. (2008). Evidence, argument and social responsibility: First-year students' experiences of information literacy when researching an essay. Higher Education Research \& Development, 27(4), 399-414.

MacDonald, R., \& Carroll, J. (2006, April). Plagiarism--A complex issue requiring a holistic institutional approach. Assessment \& Evaluation in Higher Education, 31(2), 233-245.

Marton, F., Dall'Alba, G., \& Tse, L. K. (1996). Solving the paradox of the Asian learner? In D. A. Watkins \& J. B. Biggs (Eds.), The Chinese learner: Cultural, psychological and contextual influences (pp. 6983). Hong Kong: Comparative Education Research Centre, Melbourne: Australian Council for Educational Research.

O'Regan, K. (2006). Policing - or, at least, policying - Plagiarism at one Australian university. Journal of University Teaching and Learning Practice, 3(2), 113-122, Retrieved from http://jutlp.uow.edu.au/.

Petty, R., \& Cacioppo, J. (2000). Elaboration likelihood model. In E. M. Griffin, A first look at communication theory (pp. 189-201). Boston, MA: McGraw Hill.

Valentine, K. (2006, September). Plagiarism as literacy practice: Recognizing and rethinking ethical binaries. College Composition and Communication, 58(1), 89-109.

Volet, S. E., \& Renshaw, P. (1996). Chinese students at an Australian university: Adaptability and continuity. In D. A. Watkins \& J. B. Biggs (Eds.), The Chinese learner: Cultural, psychological and contextual influences (pp. 205-220). Hong Kong: Comparative Education Research Centre, Melbourne: Australian Council for Educational Research.

Whitelaw, P. A., Henderson, F., Jose, P., Li, D. F., Gao, C. M., Shi, W. J., \& Li, Q. (2010). Investigating the efficacy of culturally specific academic literacy and academic honesty resources for Chinese students. Retrieved from http://www.olt.gov.au/project-investigating-efficacy-vu-2008 .

Yeo, S. (2006). Managing student plagiarism: Critical first-stage decision-making. HERDSA conference, University of Western Australia, 10-12 July.

Zhang, L. F., \& Sternberg, R. J. (2000). Are learning approaches and thinking styles related? A study in two Chinese populations. Journal of Psychology, 134(5), 469-490.

Zhuang, L. (2009). The challenges facing Sino-UK transnational education: An institutional experience. Journal of Knowledge-based Innovation in China, 1(3), 243-255, Retrieved from http://0www.emeraldinsight.com.library.vu.edu.au/Insight/viewPDF.jsp?contentType $=$ Article\&Filename $=\mathrm{htm}$ 1/Output/Published/EmeraldFullTextArticle/Pdf/4040010305.pdf. 


\section{Appendix A}

\section{Student Evaluation: Indicative Focus Group questions}

Have you heard about academic honesty?

What do you know about referencing styles? Do you use one [eg Harvard referencing]?

What does plagiarism mean?

What does fabricated mean?

What does collusion mean?

And then, a series of questions about the web based resources:

1. What do you like about the videos?

2. What could be better about the videos?

3 . Is any video too long?

4. Would you prefer to watch the video without the interactive questions?

5. Did you know any of the people portrayed in the video?

6. Is it possible to get overnight success?

7. Academic Literacy means 学术研究技巧 (academic study skills), thinking critically and fighting against plagiarism. How are you building these skills?

8. What does the saying "Practice makes perfect" mean to you?

9. When do you get opportunities to demonstrate your critical thinking skills?

10. What is the message behind the Shakespeare example?

\section{Appendix B}

\section{Academic Staff Evaluation: Indicative Focus Group questions}

What does academic honesty mean to you?

How would you describe plagiarism in China?

Which referencing styles do you ask students to use?

What does plagiarism mean for your teaching?

What does fabricated mean?

What does collusion mean?

And then, a series of questions about the web based resources:

1. What do you like about the videos?

2. What could be better about the videos?

3. Is any video too long?

4. Do your students prefer to watch the video without the interactive questions?

5. Did you know any of the people portrayed in the video?

6. Is it possible to get overnight success?

7. Academic Literacy means 学术研究技巧 (academic study skills), thinking critically and fighting against plagiarism. How are you building these skills?

8. What does the saying "Practice makes perfect" mean to you?

9. How do your students get opportunities to demonstrate their critical thinking skills?

10. What is the message behind the Shakespeare example?

11. What is your overall assessment of our Academic Literacy website?

12. What are your recommendations for its use in China? 


\section{Biographies}

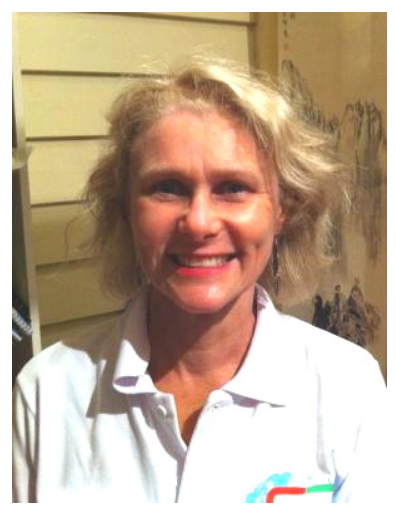

Dr Fiona Henderson is a Senior Lecturer \& Coordinator in Academic Language and Learning at Victoria University. She was co-researcher for VU's AVCC grant Improving Language and Learning Support for Offshore Students in 2005. This led to VU's annual Teaching and Learning conference with Chinese partner institutions in China and several collaborative research projects into the Scholarship of Teaching and Learning with Chinese partner institutions. She received a Carrick Citation in 2007 and a Victoria University Award in 2012. She was co-researcher for the ALTC project Investigating the Efficacy of Culturally Specific Academic Literacy Resources for Chinese students. She is currently leading an Office of Learning and Teaching funded project on Academic Integrity. Her $\mathrm{PhD}$ investigated employability skills from the perspective of Chinese employers.

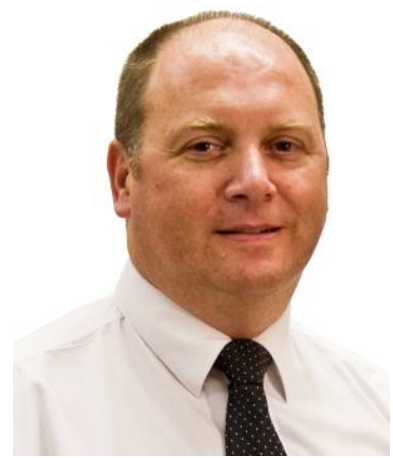

Dr Paul A Whitelaw is a Senior Lecturer in the College of Business at Victoria University where he also lectures in quantitative and computer based hospitality management systems on under graduate and post graduate programs. In 2011 Paul was the Acting Head of the School of International Business, prior to that a Senior Lecturer in the School of Hospitality, Tourism and Marketing and before that he was Foundation Executive Director of The Centre for Hospitality and Tourism Research, also at Victoria University. Along with his colleague, Fiona Henderson, he was co-researcher for the ALTC project Investigating the Efficacy of Culturally Specific Academic Literacy Resources for Chinese students and is currently leading an Office of Learning and Teaching funded project on Academic Integrity. 